\title{
Förändringar av häckfåglar på en sydsmåländsk gård från 1970- till 2010-talet
}

\author{
Changes of the breeding birds on a forest-dominated farm in southern Sweden \\ from the 1970s to the $2010 \mathrm{~s}$
}

SVEN G. NILSSON

\begin{abstract}
I compare the number of breeding birds of a 70 ha farm in a forest region of southern Sweden between the 1970s and the 2010s. The most important habitat change was replacement of 25 hectares 100 years old mixed forest by spruce plantation. Stands dominated by deciduous trees only grew older, and pastures were grazed by cattle both periods. More species decreased than increased, especially residents and tropical migrants decreased. For short distance migrants, the number of decreasing

by the spruce plantation. Species preferring deciduous forest had much higher densities in the study plot than the regional averages. Two deciduous forest species, Pied Flycatcher Ficedula hypoleuca and Marsh Tit Poecile palustris declined strongly, the latter possibly due to competition from the increasing Blue Tit Cyanistes caeruleus. The Starling Sturnus vulgaris and the Tree Pipit Anthus trivialis stands out as drastically decreasing much more than local habitat changes can explain.
\end{abstract} species were balanced by a similar number of increasing species. The density change of most species could be attributed to the replacement of the old mixed forest
Sven G. Nilsson, Stockanäs 42, S-34371 Diö, Sverige. E-mail: sveng.nilsson@telia.com

Received 22 March 2017, Accepted 21 June 2017. Editor: Robert Ekblom

Antalsförändringar för Sveriges vanligare skogsoch åkerlevande fåglar följs noga sedan 1975, men vad som hänt innan dess vet vi mycket mindre om (Ottvall m.fl. 2008, Green m.fl. 2016). Orsaker till uppmätta förändringar av fågelpopulationer spekuleras det ofta om, men först när man kan relatera lokala förändringar till vad som där hänt med olika arters habitat och föda kan man få säkrare svar. Denna undersökning av häckande fåglar på en gård i södra Småland har gjorts samtidigt som biotopförändringar också följts noga under 60 år. Gården Djäknabygd ägs sedan århundraden av Växjö stift, men ungefär hälften är sedan 2009 naturreservat. Det gäller hagmarkerna, slåtterängar och den äldre lövträdsdominerade skogen.

Djäknabygd var ett traditionellt småbruk med fem till sex mjölkkor, en till två suggor med smågrisar, tjugo till fyrtio höns och en till två hästar fram till 1960, då staten betalade mina föräldrar för att sluta med mjölkproduktion. Jag tillbringade mina första nitton år på denna gård och utförde barnarbete där i lantbruket tillsammans med min storebror Ingvar. Vi samlade också kärlväxter och pressade dem från när jag var tio år 1957. Från det- ta och följande år har jag också anteckningsböcker med noteringar om fåglar. Det var också här på hemgården som jag under 1950- och 1960-talet lärde mig alla lokala fåglars läten, habitat m.m. Samtidigt blev kunskapen om alla naturförhållanden på gården mycket detaljerad, t.ex. om var det fanns ihåliga träd.

Syftena med denna uppsats är att noga dokumentera fågellivet på en gård i södra Sveriges skogsbygd under två tidsperioder samt diskutera orsakerna till de förändringar som jag funnit. Detaljerade inventeringar av häckande och revirhållande fåglar gjordes 1972-1980 och 2008-2016.

\section{Undersökningsområde}

Det inventerade området är 70 hektar, främst på gården Djäknabygd, Stenbrohults socken. Gårdens gränser framgår av karta i Nilsson (2006). De delar av gården som inte ingår är den nordligaste ändan som ligger mer än 100 m norr om den gamla kyrkvägen mellan Råshult och kyrkan. Dessutom ingår hagmarken på Prästgården som ligger intill Djäknabygd och öster om den grävda kanalen mellan 
Biersjön och sjön Möckeln; detta hagmarksområde kallat Prästängen är ca 4 hektar stort.

På 1970-talet dominerades den tidigare utmarken på Djäknabygd av grandominerad blandskog, där barrträden var omkring 100 år gamla men de äldsta var omkring 150 år (Nilsson 2006). Denna skogsmarks struktur och trädslagssammansättning under 1970-talet framgår av Nilsson (1979a), delområdena S1 och S2. I dessa gamla skogar utgjorde granen $70-80 \%$, tallen $15-20 \%$ och lövträd främst björk 5-15\%. Dessutom fanns ganska mycket ung ek och bok i den barrträdsdominerade skogen, se tätheter av dessa trädslag i Nilsson (1985); "sprucedominated forest" är från den gamla skogen i Djäknabygd. Några hektar av dessa äldre skogar avverkades 1974, och nästan all övrig äldre barrskog slutavverkades 1981 och 1984. På hyggena lämnades spridda äldre tallar, men de avverkade områdena planterades sedan med gran. Denna plantageskog av gran som hade lövröjts var alltså 30-35 år gammal under inventeringsperioden 2008-2016, men även några hektar äldre olikåldrig grandominerad blandskog fanns ännu kvar. Dessutom har det under båda undersökningsperioderna funnits en tallhögmosse, ursprungligen på ca 6 hektar, varav 2/3 hittills lämnats orörd. Däremot dikades laggarna med kärrvegetation omkring tallmossen ut efter att hygget omkring tagits upp 1984. Rikligt med självföryngrad gran har därefter etablerats längs dikena.

På den tidigare inägomarken kring gårdscentrum dominerar lövträden, främst bok, ek och björk men där fanns även ca 15\% gran på 1970-talet. Dessutom växer hassel, asp, skogslind, klibbal, avenbok, skogslönn, apel, rönn och skogsalm spritt i de tidigare inägorna. Södra stambanan går genom gårdens östra del av inägomarken. Den 17 hektar stora delen öster om järnvägen utgör område H i Nilsson (1979a), där mer exakt information finns om delområdets träd och buskar. De äldsta träden där finns i bokbackar på totalt ungefär ett hektar och träden har åldersbestämt till 200-290 år (Mats Niklasson, muntl.). De flesta av dessa ca 50 gamla bokar är ihåliga. Ekarna i området har inte åldersbestämda men de flesta är inte så gamla, utan flertalet sannolikt 80-100 år. Efter en markbrand i maj 1974 avverkade markägaren Växjö stift ca 0,5 hektar med gammal ädellövskog öster om järnvägen och granplanterade detta område som tidigare innehöll många ihåliga ädellövträd. Efter att området öster om järnvägen utnämnts till "kyrkoreservat" avverkades dock den planterade granen 2001. Betet upphörde därefter under några år öster om järnvägen, då björk föryngrade sig rikligt. Mycket av denna ungbjörk har avverkats åren 2014 och 2016, eftersom detta nu är en hagmark i naturreservatet Stenbrohult.

Hela området öster om järnvägen har betats av nötkreatur och vissa år av en eller två hästar under båda undersökningsperioderna. Under 1970-talet gick rekryteringskvigor från Prästgården här, medan det under senare år betats av dikor av rasen rödkulla. Hälften av ängsmarken öster om järnvägen fårbetades intensivt 2005-2008, men detta område betades av fem ponnyhästar fr.o.m. maj under 2009. Hela området öster om järnvägen betades av nötkreatur och hästar under augusti-oktober 2009. Hagmarkerna öster om järnvägen lämnades utan hävd 2010, förutom tre kor med kalvar som betade ca tio dagar efter midsommar. Det mesta av det kvarstående gräset brändes av i mitten av april 2011. Området öster om järnvägen betades av nötkreatur under sommar och höst 2011-2016, samt även av en till två hästar några år. Samtliga nötkreatur som betat $\mathrm{i}$ området öster om järnvägen sedan 2008 har varit av lantrasen rödkulla. Sedan 2011 har det i hagmarken öster om järnvägen även funnits två örtrika slåtterängar på ca ett hektar, som slagits av i slutet av augusti med senare efterbete av nötkreatur. Även väster om järnvägen har det funnits mindre slåtterängar under båda tidsperioderna. Hagmarken på östra Prästgården har betats av nötkreatur båda undersökningsperioderna.

Inom hela området har det funnits många små kärr, som dock oftast helt torkat ut under sommaren. De som fanns i och intill de avverkade områdena 1974-1984 dikades ut. Däremot har de tiotal små kärren öster om järnvägen lämnats orörda. Här har t.o.m. ett par kärr haft högre vattenstånd på senare år när äldre diken har vuxet igen naturligt.

Under 1970-talet matades fåglarna vintertid med havre och talg vid boningshuset, men det har inte skett under senare årtionden. Däremot har fågelmatning förekommit i Stenbrohults kyrkby väster om och i Råshults by öster om undersökningsområdet. Under 1970-talet fanns från början 30 holkar inom området som fram till 1980 successivt minskade till ca 20, men under 2008-2016 bara några få holkar. Förekomsten av naturhål i gamla lövträd har varit riklig på den f.d. inägomarken under båda tidsperioderna. Under 1970-talet hittades fågelbon inuti 43 hålträd, varav flera hål utnyttjades i vissa träd.

\section{Metod}

Alla år, förutom 1980, har undersöksområdet besökts minst två gånger i veckan från mitten/slutet av mars till slutet av juni. Den utsträckta inventeringsperioden under vår-sommar baserades på att olika fåglarnas sångaktivitet toppar under olika 
tidsperioder (Nilsson 1974b, 1977). Området genomkorsades längs $\mathrm{i}$ förväg bestämda rutter med $100 \mathrm{~m}$ avstånd (se figur i Nilsson 1974a). Rutternas start alternerade mellan södra och norra ändan av området och varannan gång gick jag mellan de tidigare 100-meters linjerna. Dagar med regn och blåst gjordes inga inventeringar. Alla fågelobservationer ritades in med artkoder på en besökskarta med kompletterande noteringar i en anteckningsbok. Varje inventering startade kring soluppgången hela säsongen och varade fyra till fem timmar per besök. Åren 1972-1979 användes en utökad karteringsmetod med årligen 21-28 morgonkarteringar kompletterat med boinventeringar av trastar, mesar, stjärtmes, nötväcka och stare. Boinventeringarna gjordes främst på eftermiddagarna och funna bon följdes upp med några dagars mellanrum för att konstatera häckningsutfallet (Nilsson 1984). Flera besök gjordes även kvällstid och förnätter i marsapril för att inventera sjungande trastar, ugglor, morkulla och enkelbeckasin. Min metod påminner mycket om den som beskrivs av Tomiałojć (1980). År 1980 karterades fåglarna under tio morgonbesök och några kvällsbesök april-juni, med boletning främst för stare. År 1980 inventerades inte de vanligaste arterna noga, förutom stare, och inte heller de nattaktiva arterna.

Särskild uppmärksamhet ägnades alla år åt samtidiga observationer av sjungande fåglar och samtidigt aktiva bon. När det gäller hackspettar noterades också om möjligt kön, eftersom båda könen kan trumma. Många revirhävdande fåglar flyttar snabbt mellan olika platser i reviren, varför sådana förflyttningar noterades noga. Det gällde även observationer strax utanför undersökningsområdet, särskilt för arter med stora revir. Utan dessa noteringar av samtidigt sjungande/trummande och snabbt förflyt-

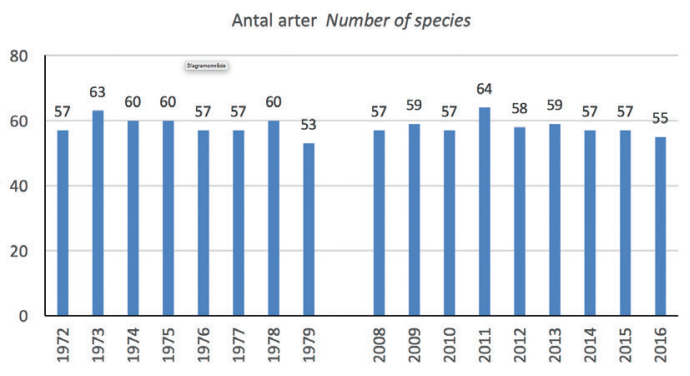

Figur 1. Antal arter de undersökta åren på gården Djäknabygd.

Number of species in the investigated years on the farm Djäknabygd. tande individer kan man lätt överskatta antal revir. Se vidare tidigare beskrivningar av metoden (Nilsson 1977, 1979a, 1979b).

Under åren 2008-2016 har området besökts lika ofta som 1972-1979, men de vanliga arterna har inte ägnats lika stor uppmärksamhet som tidigare. Riktad boletning har bara använts under senare år för stare och stjärtmes, men tidigare erfarenheter har använts för att utvärdera de observationer som gjorts av t.ex. trastar. De särskilt kvälls- och nattaktiva arterna har räknats vid flera kvälls- eller gryningsbesök per år. Särskilt har förekomsten av i trakten ovanligare arter följa upp särskilt noga även under senare år.

Vid utvärderingen av observationer har revirhävdande individer under en period på minst sju dagar på en plats bedömts som ett revir. Dessutom har revirhävdande individer under kortare perioder samt revir med mindre än halva reviret $\mathrm{i}$ området noterats. Ladusvalan har alla år häckat $100 \mathrm{~m}$ väster om och ibland i en lada $200 \mathrm{~m}$ öster om undersökningsområdet och har också alla år sökt föda över områdets hagmarker, men har ändå inte tagits med här. Fåglar som uppenbarligen sjungit under flyttning, t.ex. gransångare i april, samt bergfink och rödvingetrast under sträcktid har inte bedömts som revirhävdande. På samma sätt har överflygande sjöfåglar under häckningstid, men som inte häckat inom området, uteslutits.

Eftersom mycket noggranna täthetsberäkningar gjort på den undersökta gården kan det vara intressant att jämföra med de abundanser som anges för Kronobergs län i Ottosson m.fl. (2012). För att räkna ut tätheten i länet har det antal par som anges i boken dividerats med länets landyta på $8488 \mathrm{~km}^{2}$. För de vanligaste arterna har bara tätheter räknats ut på Djäknabygd från de år antalet revir bedömts vara noga inventerat.

\section{Resultat}

Antal revirhävdande arter har varierat mellan åren, men har årligen varit omkring 60 både under 1970och 2010-talen (Figur 1). Totalt inräknades 77 arter under 1970-talet och 72 arter under motsvarande 9-årsperiod nyligen (Appendix). Av de under senare år "nya" arterna är alla fem kortdistansflyttare (Tabell 1), även om gransångare kanske inte ska räknas som ny då en gransångare sjöng mitt i området 26 och 28 juni 1972. Av de åtta försvunna arterna är däremot fyra stannfåglar, medan tre är kortflyttare och göktytan tropikflyttare. Skata har visserligen besökt gården även under senare år, men bara tillfälligt. Skatan häckar fortfarande årligen med vardera ett till två par i Stenbrohults kyrkby och i Råshults by intill 
Tabell 1. Arter som ökat eller minskat sedan 1970-talet på gården Djäknabygd i förhållande till arternas flyttningsstrategier. Long-term species population trends at the farm Djäknabygd in relation to migratory habits.

\begin{tabular}{|c|c|c|c|}
\hline & Flyttningsstrategi $\mathrm{Migr}$ & ion strategy & \\
\hline & $\begin{array}{l}\text { Stannfåglar } \\
\text { Residents }\end{array}$ & $\begin{array}{l}\text { Kortflyttare } \\
\text { Short distance migrants }\end{array}$ & $\begin{array}{l}\text { Tropikflyttare } \\
\text { Tropical migrants }\end{array}$ \\
\hline $\begin{array}{l}\text { Nya arter } \\
\text { New species }\end{array}$ & & $\begin{array}{l}\text { Grågås } \\
\text { Anser anser } \\
\text { Trana } \\
\text { Grus grus } \\
\text { Skogsduva } \\
\text { Columba oenas } \\
\text { Gransångare } \\
\text { Phylloscopus collybita } \\
\text { Sävsparv } \\
\text { Emberiza schoeniclus }\end{array}$ & \\
\hline $\begin{array}{l}\text { Ökning } 50-100 \% \\
\text { Increase } 50-100 \%\end{array}$ & $\begin{array}{l}\text { Blåmes } \\
\text { Cyanistes caeruleus }\end{array}$ & $\begin{array}{l}\text { Dubbeltrast } \\
\text { Turdus viscivorus } \\
\text { Stenknäck } \\
\text { C. coccothraustes }\end{array}$ & $\begin{array}{l}\text { Grå flugsnappare } \\
\text { Muscicapa striata }\end{array}$ \\
\hline $\begin{array}{l}\text { Minskning } 25-50 \% \\
\text { Decrease } 25-50 \%\end{array}$ & $\begin{array}{l}\text { Nötskrika } \\
\text { Garrulus glandarius } \\
\text { Talgoxe } \\
\text { Parus major } \\
\text { Trädkrypare } \\
\text { Certhia familiaris }\end{array}$ & $\begin{array}{l}\text { Björktrast } \\
\text { Turdus pilaris } \\
\text { Taltrast } \\
\text { Turdus philomelos } \\
\text { Koltrast } \\
\text { Turdus merula } \\
\text { Rödhake } \\
\text { Erithacus rubecula } \\
\text { Grönsiska } \\
\text { Carduelis spinus } \\
\end{array}$ & $\begin{array}{l}\text { Grönsångare } \\
\text { Phylloscopus sibilatrix }\end{array}$ \\
\hline $\begin{array}{l}\text { Minskning } 50-75 \% \\
\text { Decrease } 50-75 \%\end{array}$ & $\begin{array}{l}\text { Svartmes } \\
\text { Periparus ater } \\
\text { Tofsmes } \\
\text { Lophophanes cirstatus } \\
\text { Entita } \\
\text { Poecile palustrios } \\
\text { Talltita } \\
\text { Poecile montanus }\end{array}$ & $\begin{array}{l}\text { Kungsfågel } \\
\text { Regulus regulus } \\
\text { Domherre } \\
\text { Pyrrhula pyrrhula } \\
\text { Bofink } \\
\text { Fringilla coelebs } \\
\text { Järnsparv } \\
\text { Prunella modularis }\end{array}$ & $\begin{array}{l}\text { Rödstjärt } \\
\text { Ph. phoenicurus } \\
\text { Trädgårdssångare } \\
\text { Sylvia borin } \\
\text { Lövsångare } \\
\text { Phylloscopus trochilus } \\
\text { Svartvit flugsnappare } \\
\text { Ficedula hypoleuca } \\
\text { Törnskata } \\
\text { Lanius collurio }\end{array}$ \\
\hline $\begin{array}{l}\text { Minskning }>75 \% \\
\text { Decrease }>75 \%\end{array}$ & & $\begin{array}{l}\text { Stare } \\
\text { Sturnus vulgaris }\end{array}$ & $\begin{array}{l}\text { Trädpiplärka } \\
\text { Anthus trivialis }\end{array}$ \\
\hline $\begin{array}{l}\text { Försvunna arter } \\
\text { Disappeared species }\end{array}$ & $\begin{array}{l}\text { Tjäder } \\
\text { Tetrao urogallus } \\
\text { Fasan } \\
\text { Phasianus colchicus } \\
\text { Skata } \\
\text { Pica pica } \\
\text { Pilfink } \\
\text { Passer montanus }\end{array}$ & $\begin{array}{l}\text { Kaja } \\
\text { Coloeus monedula } \\
\text { Brandkronad kungsfågel } \\
\text { Regulus ignicapillus } \\
\text { Gulsparv } \\
\text { Emberiza citrinella }\end{array}$ & $\begin{array}{l}\text { Göktyta } \\
\text { Jynx torquilla }\end{array}$ \\
\hline
\end{tabular}


Tabell 2. Genomsnittliga tätheter (revir/ $/ \mathrm{km}^{2}$ ) av häckfåglar på gården Djäknabygd på 1970-talet, motsvarande täthet 20082016 samt framräknad medeltäthet för Kronobergs län från boken Fåglarna i Sverige.

Average density (territories $/ \mathrm{km}^{2}$ ) of some species at the farm Djäknabygd in the 1970s, corresponding density in 2008-2016, and calculated mean density for Kronoberg county (G län) according to Ottosson et al. (2012).

\begin{tabular}{|c|c|c|c|}
\hline Art Species & 1970-tal & 2010-tal & G län \\
\hline Morkulla Scolopax rusticola & 3,9 & 3,3 & 2,8 \\
\hline Ringduva Columba palumbus & 7,0 & 8,1 & 4,2 \\
\hline Större hackspett Dendrocopos major & 4,6 & 4,4 & 0,7 \\
\hline Nötskrika Garrulus glandarius & 8,8 & 6,5 & 2,9 \\
\hline Stjärtmes Aegithalos caudatus & 2,9 & 3,0 & 0,3 \\
\hline Talgoxe Parus major & 34 & 18 & 16 \\
\hline Blåmes Cyanistes caeruleus & 8,6 & 14 & 4,5 \\
\hline Svartmes Periparus ater & 9,6 & 4,1 & 5,2 \\
\hline Tofsmes Lophophanes cristatus & 2,5 & 0,8 & 2,4 \\
\hline Entita Poecile palustris & 10 & 4,9 & 1,6 \\
\hline Talltita Poecile montanus & 4,3 & 1,5 & 1,4 \\
\hline Nötväcka Sitta europaea & 8,9 & 9,4 & 1,2 \\
\hline Trädkrypare Certhia familiaris & 11 & 7,8 & 6,5 \\
\hline Gärdsmyg Troglodytes troglodytes & 6,7 & 6,7 & 5,9 \\
\hline Taltrast Turdus philomelos & 27 & 14 & 7,1 \\
\hline Koltrast Turdus merula & 25 & 15 & 14 \\
\hline Rödhake Erithacus rubecula & 58 & 29 & 21 \\
\hline Svarthätta Sylvia atricapilla & 13 & 11 & 12 \\
\hline Trädgårdssångare Sylvia borin & 18 & 7,5 & 5,3 \\
\hline Ärtsångare Sylvia curruca & 2,7 & 1,2 & 1,8 \\
\hline Lövsångare Phylloscopus trochilus & 69 & 28 & 41 \\
\hline Grönsångare Phylloscopus sibilatrix & 11 & 5,9 & 0,7 \\
\hline Kungsfågel Regulus regulus & 27 & 11 & 21 \\
\hline Grå flugsnappare Muscicapa striata & 1,8 & 3,5 & 2,9 \\
\hline Svartvit flugsnappare Ficedula hypoleuca & 16 & 5,6 & 5,5 \\
\hline Järnsparv Prunella modularis & 19 & 8,1 & 3,5 \\
\hline Trädpiplärka Anthus trivialis & 24 & 5,4 & 7,1 \\
\hline Törnskata Lanius collurio & 2,5 & 0,6 & 0,2 \\
\hline Stare Sturnus vulgaris & 21 & 2,5 & 2,4 \\
\hline Stenknäck Coccothraustes coccothraustes & 1,1 & 3,0 & 0,1 \\
\hline Grönfink Carduelis chloris & 2,4 & 2,7 & 1,8 \\
\hline Grönsiska Carduelis spinus & 7,0 & 3,8 & 2,0 \\
\hline Domherre Pyrrhula pyrrhula & 4,0 & 3,0 & 1,1 \\
\hline Bofink Fringilla coelebs & 47 & 29 & 45 \\
\hline
\end{tabular}


undersökningsområdet.

Av de stannfåglar som haft en trend i området sedan 1970-talet har hela elva arter minskat eller försvunnit, medan bara blåmesen ökat (Tabell 1). Blåmesen är en art som delvis lämnar området vintertid (egna observationer) och kunde kanske lika gärna anses vara en kortflyttare. Bland kortdistansflyttarna har sju arter ökat eller tillkommit, medan tretton arter minskat eller försvunnit. Bland tropikflyttande fåglar med ändrad täthet bedöms bara grå flugsnapparen ha ökat något, medan däremot åtta arter minskat eller försvunnit. Sammantaget har således betydligt fler arter minskat än ökat på gården Djäknabygd de senaste 45 åren. Det gäller särskilt stannfåglar och tropikflyttare.

Under åren 1972-1979, då noggranna täthetsberäkningar gjordes även för de vanligaste arterna, var mediantätheten på gården 579 revir per kvadratkilometer (bara arter med minst ett helt revir i området medtagna). Den högsta tätheten var 657 revir per kvadratkilometer år 1975 och den lägsta 427 efter den kalla vintern 1979. Tätheten i det varierade lövskogs- och hagmarks-området öster om järnvägen var 541 revir per kvadratkilometer år 1976 (område H i Nilsson 1979a). Tätheten i den gamla barrskogen var 481 revir per kvadratkilometer år 1977 (managed forest i Nilsson 1979b). Uppenbarligen varierade tätheten inte så mycket mellan olika naturtyper på gården under 1970-talet. Tätheten under senare år har varit betydligt lägre, men oftast drygt 300 revir per kvadratkilometer, men med stora variationer. Lägst täthet fanns i granplantagerna, men inga exakta beräkningar har gjorts.

För en del arter överensstämmer de tätheter som jag fann ungefär med de som räknats fram för Kronobergs län från Ottosson m.fl. (2012), men flera arter avviker markant (Tabell 2). Grönsångare, nötväcka, stjärtmes och stenknäck har mer än åtta gånger högre täthet på gården Djäknabygd jämfört med uppgifterna i boken Fåglarna i Sverige. Större hackspett, blåmes, entita, törnskata och domherre har tre till sex gånger så hög täthet på gården.

Svartvit flugsnappare, trädpiplärka och stare har minskat drastiskt på Djäknabygd sedan 1970-talet, så att de gått från att ha flera gånger så hög täthet som räknats fram för Kronobergs län från boken Fåglarna i Sverige till att nu ha ungefär samma tätheter som anges i boken (Tabell 2). På liknande sätt har tätheterna för de på 1970-talet vanligaste arterna bofink, talgoxe, taltrast, koltrast, rödhake, trädgårdssångare, lövsångare och kungsfågel minskat så att de nu ligger i nivå med eller lägre än skattningarna för Kronobergs läns genomsnittliga tätheter.

\section{Diskussion}

Det har skett stora förändringar i häckfågelfaunan på gården Djäknabygd under de senaste 45 åren, men antalet arter har varit högt under båda de undersökta tidsperioderna. En hel del av förändringarna kan sättas i samband med biotopförändringar, medan andra tycks bero på andra faktorer. Sammantaget har betydligt fler arter minskat än ökat på gården Djäknabygd de senaste 45 åren. Det gäller särskilt stannfåglar och tropikflyttare.

Att skata, pilfink och gulsparv har försvunnit kan bero på att vintermatningen upphörde vid boningshuset omkring 1990. Huvudsakligen erbjöds tidigare havre och talg, producerat på gården. Andra viktiga faktorer för dessa arter är sannolikt att sädesodlingen i trakten, som fortfarande var vanlig på många gårdar under 1970-talet, har minskat betydligt sedan dess. Detta kan också vara orsak till att kajan försvunnit från gården, trots att många lämpliga hålträd ännu finns kvar. Både kaja och pilfink häckar dock fortfarande på Stenbrohults prästgård, där årligen åkrar har såtts med blandsäd av havre och korn även under senare år.

Den mest drastiska förändringen av biotopen på gården är att ca 25 hektar gammal grandominerad blandskog ersattes av granplantager. Från att skogen varit luckig, olikåldrig med flera trädslag, och med de äldsta träden 100-150 år gamla, blev barrskogen en jämnårig granplantering med bara ett litet inslag av björk och tall (Nilsson 2006). Under 2008-2016 har barrskogen därför dominerats av 30-35 år gamla granplantager. Dessutom fanns det drygt ett hektar rena granbestånd från plantering av hagmarker 1960 (nästan lika mycket av dessa plantager blåste ned i stormen 2005), samt några hektar ungefär hundraårig grandominerad blandskog. Minskningen av svartmes, tofsmes, talltita, trädkrypare, rödhake, grönsångare, kungsfågel, järnsparv, grönsiska, domherre och bofink kan direkt sättas i samband med avverkningen av gammal grandominerad blandskog. Detta framgår från hur reviren fördelas under de två tidsperioderna (opublicerade artkartor).

Det är intressant att brandkronad kungsfågel under tre år på 1970-talet hävdade revir på olika platser i den gamla grandominerade skogen, där det fanns inslag av tall, björk, ek, bok och asp. Trots att den brandkronade kungsfågeln ökat markant i Sverige sedan dess har den inte återvänt till gården. Även en lundsångare hävdade revir under tre veckor i den gamla grandominerade skogen 1978. En annan intressant art i den gamla barrsko- 
gen var den tretåiga hackspetten. En hona sågs 13 april 1974 samt 2 november 1974 och en hane tre gånger under 9-19 april 1975. En hane sågs även 30 december 1981 (Ingvar Nilsson). På kyrkans tre anslutande gårdar i Stenbrohult fanns vid denna tid över 100 hektar med drygt 100-årig grandominerad skog. Det är troligt att ett par av tretåig hackspett då fanns i denna skog, åtminstone under några år. Under 1970-talet noterades den tretåiga hackspetten i två andra områden vid sjön Möckeln, även under häckningstid. Efter att de gamla barrskogarna vid sjön avverkats finns inga fler observationer av tretåig hackspett.

Det är viktigt att uppmärksamma hur drastiskt även markvegetationen har ändrats i gårdens barrträdsdominerade skogar de senaste 40 åren. På 1970-talet var marken nästan helt mosstäckt i dessa gamla skogar, bärris av blåbär och lingon täckte 60-80\% av marken och kruståtel under 50\% (Nilsson 2006). I de nya granplantagerna finns mest några vanliga mossor, fläckar med kruståtel och barr på marken, men nästan inget bärris. Att det är skogsbruket som ligger bakom bärrisets minskning framgår tydligt av att det $\mathrm{i}$ en kraftledningsgata genom norra delen ännu växer rikligt med högt blåbärs- och lingonris.

Blåbärsris minskar starkt med ökande täthet av gran, men ökar successivt till en platå när skogen blir över 80 år gammal (Hedwall m.fl. 2013). Fjärilslarver som lever på blåbärsris är en viktig föda för tjäderkycklingar och för insektsätande tättingar (Atlegrim 1989). Blåbärsrisets drastiska minskning i barrskogen kan bl.a. förklara tjäderns försvinnande från Djäknabygd, kanske i kombination med att tuvullens blomning minskat på tallhögmossen efter igenväxning (egna observationer). Senast jag såg en tjäderkull på gården var i juni 1963, men tjäder sågs under häckningstid även tre år under 1970-talet. Även för små insektsätande fåglar, samt kanske också för taltrast och koltrast, kan den drastiska minskningen av blåbärsris vara väl så viktig som barrskogens yngre ålder för att förklara minskningen av fåglarna. Detta behöver undersökas mer ingående, för att kunna förklara fåglars populationsförändringar i skogsmark. Både taltrast och koltrast tycks dock generellt ökat något på längre sikt i Sverige (Green m.fl. 2016).

De nötkreatursbetade hagmarkerna har varit ungefär lika stora båda undersökningsperioderna. Därför går det inte att förklara göktytans försvinnande samt trädpiplärkans och starens drastiska minskningar utifrån lokala habitatförändringar. Visserligen fanns många revir av piplärkan i den gamla luckiga barrskogen, men minskningen av trädpiplärkan kan inte bara förklaras av denna skogs försvinnande. Antalet revir har ungefär halverats i hagmarkerna sedan början av 1970-talet. Då fanns även tre revir trädpiplärka på tallmossen, som märkbart vuxit sig tätare sedan laggkärren dikats ut. Under senare år har trädpiplärkan helt försvunnit från skogsmarken, där det i början av 1970-talet fanns mer än tio revir i luckor i den barrträdsdominerade skogen. Det är anmärkningsvärt att trädpiplärkans bestånd på Djäknabygd halverades redan på 1970-talet, något som alltså skedde innan den landstäckande övervakningen av fågelfaunan började 1975. Orsaken till denna tidiga minskning finns inte i habitatförändringar på Djäknabygd, utan troligen på övervintringsområdet i Afrika. Notervärt är att även i Storbritannien minskade trädpiplärkan markant under 1970-talet.

Stararna på gården har hela tiden häckat i naturhål och mängden av dessa har bara ändrats marginellt. Flera ihåliga lövträd har avverkats 1974-1984, men hackspettarna har senare hackat ut nya hål, främst $i$ aspar. Troligen ligger miljöändringar på flyttningsoch/eller övervintringsområdena åtminstone delvis bakom minskningar av göktyta, stare och trädpiplärka. Under de senaste 40 åren har dessa tre arter minskat markant i Sverige (Green m.fl. 2016), men orsakerna är inte uppenbara. På Kullaberg i Skåne har göktyta, stare och trädpiplärka minskat med mer än 90\% från 1974 till 2014, trots att ytan av betade hagmarker inte minskat där (Nilsson \& Peterz 2016). Arterna har sina utbredningscentra $i$ Europa söder om mitt undersökningsområde, varför klimatförändringar i form av ökande temperaturer inte heller verkar ligga bakom minskningarna. Ett varmare klimat borde leda till ökning i norra delen av utbredningsområdena om andra faktorer vore oförändrade.

Flera av de nytillkomna och ökande arterna på gården Djäknabygd är sådana som generellt ökat i södra Sverige under de senaste 40 åren (Ottvall m.fl. 2008, Green m.fl. 2016), förutom skogsduva, grå flugsnappare och sävsparv som minskat. Både skogsduvan och flugsnapparen har ökat i Sverige under senare år, men minskat sedan 1975. Sävsparven har dock minskar inom alla tidshorisonter. Att sävsparven hävdat revir på Djäknabygd under senare år kan sättas i samband med att betesmarken öster om järnvägen blivit blötare efter att gamla diken vuxit igen. Kanske kan detta även förklara att den generellt minskande enkelbeckasinen hållit ställningarna på gården.

Den totala fågeltätheten på gården Djäknabygd var inte anmärkningsvärt hög ens på 1970-talet. I flera äldre lövträdsdominerade blandskogar vid sjön 
Möckeln var tätheten i mitten av 1970-talet mellan 1037 och 1453 revir per kvadratkilometrar (Nilsson 1979a, 1979b, 1980). Om populationstätheten av olika arter på gården Djäknabygd jämförs med den beräknade i Kronobergs län kan den stora skillnaden för stjärtmes, blåmes, entita, nötväcka, grönsångare och stenknäck förklaras av den relativt stora ytan äldre ädellövskog på Djäknabygd och även andra gårdar kring sjön Möckeln (Rundlöf 2003). Att lövskogen blivit äldre inom området har även gynnat blåmes och stenknäck som ökat något sedan 1970-talet. Att tätheten av entita halverats på gården sedan 1970-talet kan däremot inte förklaras av förändringar av habitat. Eftersom entitan är stannfågel skulle en möjlig förklaring till artens minskning kunna vara konkurrens med den ökande blåmesen. Vid flera tillfällen har jag observerat att blåmesar tagit över bohål från entitor samma vår. Det finns indikationer på att en hög täthet av blåmes tvingar entitan att häcka $\mathrm{i}$ bohål med högre predationsrisk (Nilsson 1984). På Kullaberg har entitan minskat drastiskt från 1974 till 2014, trots att ytan lövskog ökat under perioden (Nilsson \& Peterz 2016). Under samma period har blåmesens population ökat trefaldigt på Kullaberg, i linje med min hypotes. En negativ påverkan på entitans antal från talgoxen kan inte heller uteslutas (Wittwer m.fl. 2015).

Den svartvita flugsnapparen föredrar äldre ädellövskog, men antalet holkar har minskat på Djäknabygd och arten har också minskat generellt. På 1970-talet häckade många par i holkar, men under senare år däremot mest $i$ ihåliga lövträd. För svartvita flugsnapparen är det således svårt att särskilja orsaken till minskningen från lokala habitatförändringar och andra faktorer. Det finns indikationer på att mesars konkurrens i kombination med klimatförändringar påverkat svartvita flugsnapparens population negativt (t.ex. Wittwer m.fl. 2015).

Det är välkänt att vissa stannfåglar påverkas negativt av kalla vintrar, vilket bl.a. visats för gärdsmyg, kungsfågel och nötväcka från data insamlade i Stenbrohult (Nilsson 1986, 1987). Efter den kalla vintern 1978/1979 försvann både stjärtmesen och gärdsmygen helt från Djäknabygd, men båda återkom 1980 (Appendix). Flera andra arter minskade också märkbart från 1978 till 1979. De senaste åren var 2009/2010 en kall vinter, med halverade bestånd av gärdsmyg och kungsfågel som en trolig konsekvens. Däremot kunde ingen effekt ses på stjärtmes eller nötväcka av denna kalla vinter. Den negativa effekten av en kall vinter kan dock buffras av en hög födotillgång (Nilsson 1987). Generellt är det svårt att förklara täthetsskillnader mellan de undersökta tidsperioderna med olika vinterväder. Fle- ra vintrar var ovanligt milda även under 1970-talet.

Hur generella är de förändringarna av fågelfaunan som noterats på gården Djäknabygd? De senaste 50 åren har äldre bärrisrika grandominerade barrskogar i trakten ersatts av yngre granplantager med nästan inget bärris (egna observationer). Det är därför troligt att de minskningar av barrskogslevande fåglar som jag funnit på gården Djäknabygd är typiska för södra Småland. När det gäller hagmarkerna gäller detta däremot inte, eftersom beteshävden av många hagmarker har upphört i dessa skogsbygder sedan 1950-talet. I mitt undersökningsområde finns de däremot kvar. Inte heller när det gäller de äldre lövskogarna har de bevarats lika väl på andra gårdar som på Djäknabygd. Fågelarter som har sina föredragna habitat i hagmarker och gamla lövskogar kan därför inte förväntas ha klarat sig lika bra i regionen som på den undersökta gården de senaste 45 åren.

\section{Slutsatser}

Om vi ska kunna förklara orsakerna till populationsförändringar av fåglar behövs det långvariga lokala studier som relaterar habitatförändringar till hur antal par av arterna förändras. Jämförelser mellan vad som händer i brukade områden med relativt opåverkade kan ge värdefull kunskap, vilket visats från södra Finland (Virkkala 2016). Flera slutsatser kan dras från långtidsstudien av häckande fåglar på gården Djäknabygd när jämförelser görs med hur arternas habitat ändrats. T.ex. kan den drastiska minskningen av stare och trädpiplärka på den studerade gården inte enbart förklaras av lokala habitatförändringar. Däremot kan den drastiska minskningen av gammal barrträdsdominerad blandskog med riklig förekomst av bärris förklara många arters minskning. Flertalet av lövskogsfåglarna har däremot hållit ställningarna och är betydligt vanligare på gården jämfört med i regionen omkring. Sammantaget har betydligt fler arter minskat än ökat på gården Djäknabygd de senaste 45 åren. Det gäller särskilt stannfåglar och tropikflyttare, där antalet minskande arter inte vägts upp av antalet ökande arter lika mycket som för kortdistansflyttare.

\section{Tack}

Jag tackar Ingvar Nilsson, Henrick Blank och Tomas Johansson för synpunkter samt Maj Rundlöf för figur och rättning av engelskan. 


\section{Referenser}

Atlegrim, O. 1989. Exclusion of birds from bilberry stands: Impact on insect larval density and damage to the bilberry. Oecologia 79: 136-139.

Green, M., Haas, F. \& Lindström, A. 2016. Övervakning av fåglarnas populationsutveckling. Årsrapport för 2015. Biologiska institutionen, Lunds universitet.

Hedwall, P.-O., Brunet, J., Nordin, A., Bergh, J. 2013. Changes in the abundance of keystone forest floor species in response to changes of forest structure. Journal of Vegetation Science 24: 296-306.

Nilsson, K.G. \& Peterz, M. 2016. Häckfågelfaunan på Kullaberg 2014 - resultat samt populationsförändringar sedan 1974. Anser, supplement 70: 1-40.

Nilsson, S.G. 1974a. Methods of estimating bird population densities during the winter. Ornis Scand. 5: 37-46.

Nilsson, S.G. 1974b. Fåglarnas sångaktivitet i två sydsmåländska skogsområden. Vår Fågelvärld 33: 218-221.

Nilsson, S.G. 1977. Estimates of density and population changes in Tits, Nuthatch and Treecreeper: An evaluation of the territory mapping method. Ornis Scand. 8: 9-16.

Nilsson, S.G. 1979a. Density and species richness of some forest bird communities in South Sweden. Oikos 33: 392-401.

Nilsson, S.G. 1979b. Effect of forest management on the breeding bird community in southern Sweden. Biological Conservation 16: 135-143.

Nilsson, S.G. 1980. Fågelsamhället i naturskog vid sjön Möckeln. Milvus 10: 86-91.

Nilsson, S.G. 1984. The evolution of nest-site selection among hole-nesting birds: the importance of nest predation and competition. Ornis Scand. 15: 167-175.

Nilsson, S.G. 1985. Ecological and evolutionary interactions between reproduction of beech Fagus silvatica and seed eating animals. Oikos 44: 157-164.

Nilsson, S.G. 1986. Density-independence and density-dependence in the population dynamics of the Wren Troglodytes troglodytes and the Goldcrest Regulus regulus. Vår Fågelvärld, Supplement 11: 155-160.

Nilsson, S.G. 1987. Limitation and regulation of population density in the Nuthatch Sitta europaea (Aves) breeding in natural cavities. J. Animal Ecology 56: 921-937.

Nilsson, S.G. 2006. Utmarksskogen förr i tiden - uppgifter från Linnés hembygd. Svensk Bot. Tidskr. 100: 393-412.

Ottvall, R. m.fl. 2008. Populationstrender för fågelarter som häckar i Sverige. Naturvårdsverket, Rapport 5813.

Ottosson, U. m.fl. 2012. Fåglarna i Sverige - antal och förekomst. Sveriges Ornitologiska Förening, Halmstad.

Rundlöf, M. 2003. Lövskogsbestånd och vidkroniga lövträd i Möckelnområdet. Inventering baserad på infraröda flygbilder. Länsstyrelsen i Kronobergs län, Växjö.

Tomiałojć, L. 1980. The combined version of the mapping method. Proc. VI Intern. Conf. on Bird Census Work, Göttingen: 92-106.

Virkkala, R. 2016. Long-term decline of southern boreal forest birds: consequence of habitat alteration or climate change? Biodiversity Conservation 25:151-167.

Wittwer, T., O’Hara, R.B., Caplat, P., Hickler, T. \& Smith, H.G. 2015. Long-term population dynamics of a migrant bird suggests interaction of climate change and competition with resident species. Oikos 124:1151-1159.

\section{Summary}

The breeding and territorial birds on a farm in the forest dominated region of central southern Sweden were counted both in 1972-1980 and 2008-2016. The study area of 70 hectare was visited about twice weekly from the end of March to the end of June in the early mornings. Visits started around sunrise and each visit usually lasted 4-5 hours. Observations of all birds were noted down on maps and in a note book, with special attention to movements of individuals and simultaneously singing birds of a species. Later in the day, nests were searched for, and the number of long-tailed tit Aegithalos caudatus, song trush Turdus philomelos, common blackbird Turdus merula and starling Sturnus vulgaris were mainly estimated from the number of nests found. The nests of all species were later visited to note their status and if birds were still present at the nests. The census method used is similar to the method described by Tomiałojć (1980).

Observations of species with large territories were also noted adjacent to the study area, and only if the majority of the home range was estimated to be within the study area one territory was noted. Less than half of the territory in the study plot is noted as X in the Appendix, which also is valid for territorial birds using the plot less than 7 consecutive days in a year. Singing birds obviously on migration are not included in this study.

The most important change of habitats in the study plot is the cutting of about 25 hectare of around 100 year old spruce-dominated mixed forest 1981-1984 and the plantation of spruce on these cuttings. At the same time, stands dominated by deciduous trees have grown older and the pastures have been grazed by cattle both study periods. The number of nest-boxes decreased during the 1970s from about 30 to 20, and during 2008-2016 only a few boxes were present. Only small boxes were available. The number of hollow trees, mainly deciduous species, were common in both periods. In the 1970s bird nests were found in natural cavities in 43 trees, with more than one cavity used in several trees.

More species decreased than increased between the two study periods, especially resident species and tropical migrants. For short distance migrants on the other hand, the number of decreasing species were balanced by about the same number of increasing species (Table 1). Density changes between the two study periods can be compared with the published estimated territory density in the region (Table 2). For most species, these local chang- 
es in densities can be attributed to the replacement of old mixed forest by 30-35 years old spruce plantations (unpublished species maps). Species preferring deciduous forest had much higher densities in the study plot than the regional averages (Table 2). However, the pied flycatcher Ficedula hypoleuca preferring deciduous forests decreased strongly. Since this species mainly bred in nest boxes in the 1970s, the change in numbers can be caused by habitat changes both within the study plot and elsewhere. Another species also preferring deciduous forest, the resident marsh tit Poecile palustris, also decreased possibly due to competition from the increasing blue tit Cyanistes caeruleus. On several occasions pairs of marsh tits were seen to be driven away from natural cavities, were they had started nest building, by blue tits.

Two species, the starling Sturnus vulgaris and the tree pipit Anthus trivialis, stands out as drastically decreasing much more than local habitat changes can explain. The tree pipit disappeared from the forests between the study periods, but also decreased in the local pastures without any obvious change in management. The starlings mainly foraged in the pasture and the number of suitable tree cavities did not change noticeably. All starlings used hollow trees in both study periods and did not use the nest boxes, which were possibly too small for this species. The decrease of both the starling and the tree pipit seem mainly to be caused by factors outside the study area.

Appendix. Antal revir/par av fåglar på gården Djäknabygd, södra Småland under två tidsperioder. X betyder del av revir eller revirhävdande/förekomst under kortare tid än 7 dagar under häckningstid ett visst år. Fet siffra eller x betyder konstaterad häckning. Ett + efter en siffra anger att det är en minimisiffra och att det verkliga antalet kan vara större.

Number of territories or pairs at two different time-period at the farm Djäknabygd. X means part of a territory or singing/occurrence during the breeding period during less than 7 days in a year. Fat figures mean that breeding was confirmed. A + after a figure denote a minimum figure, with the actual number possibly higher. 


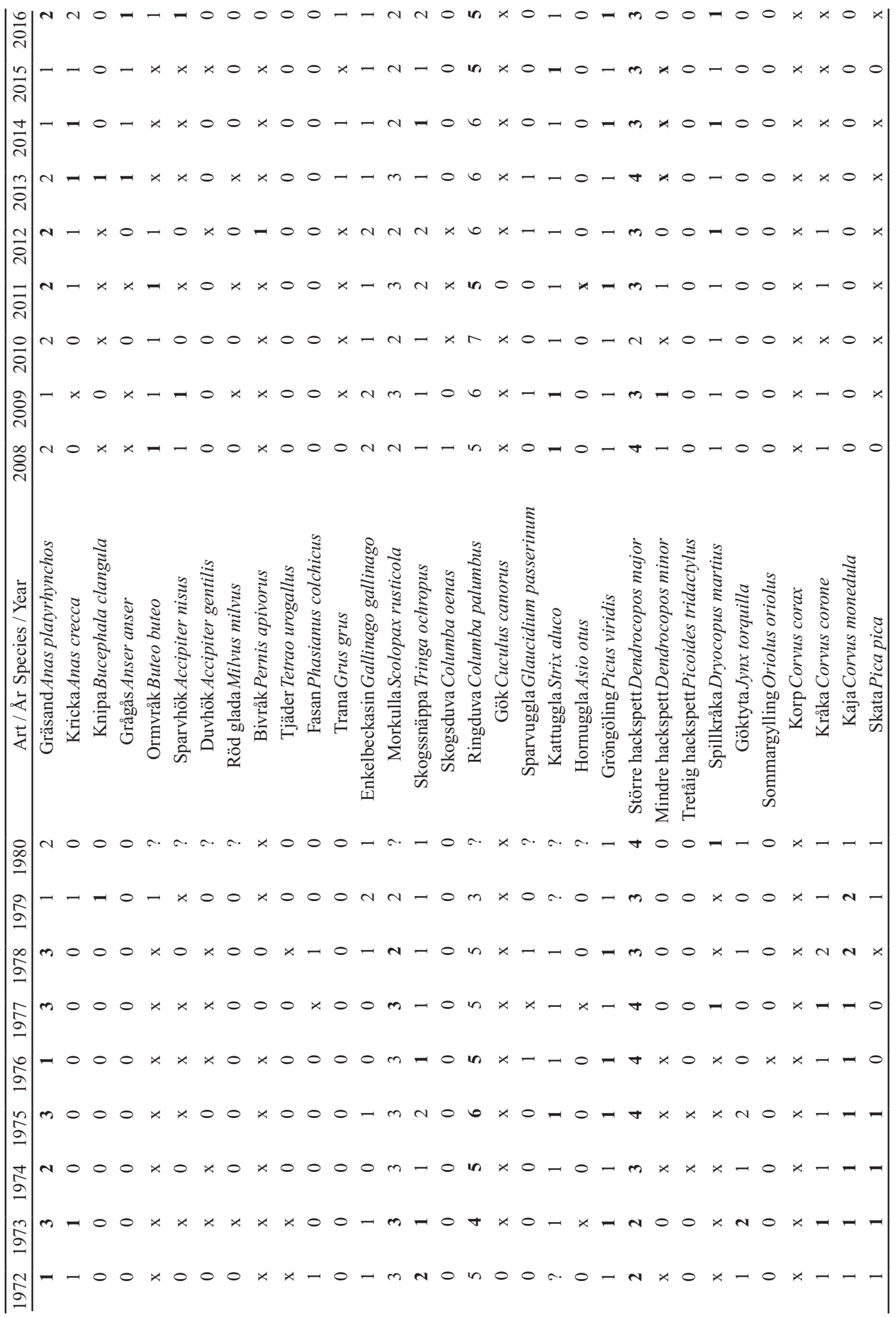




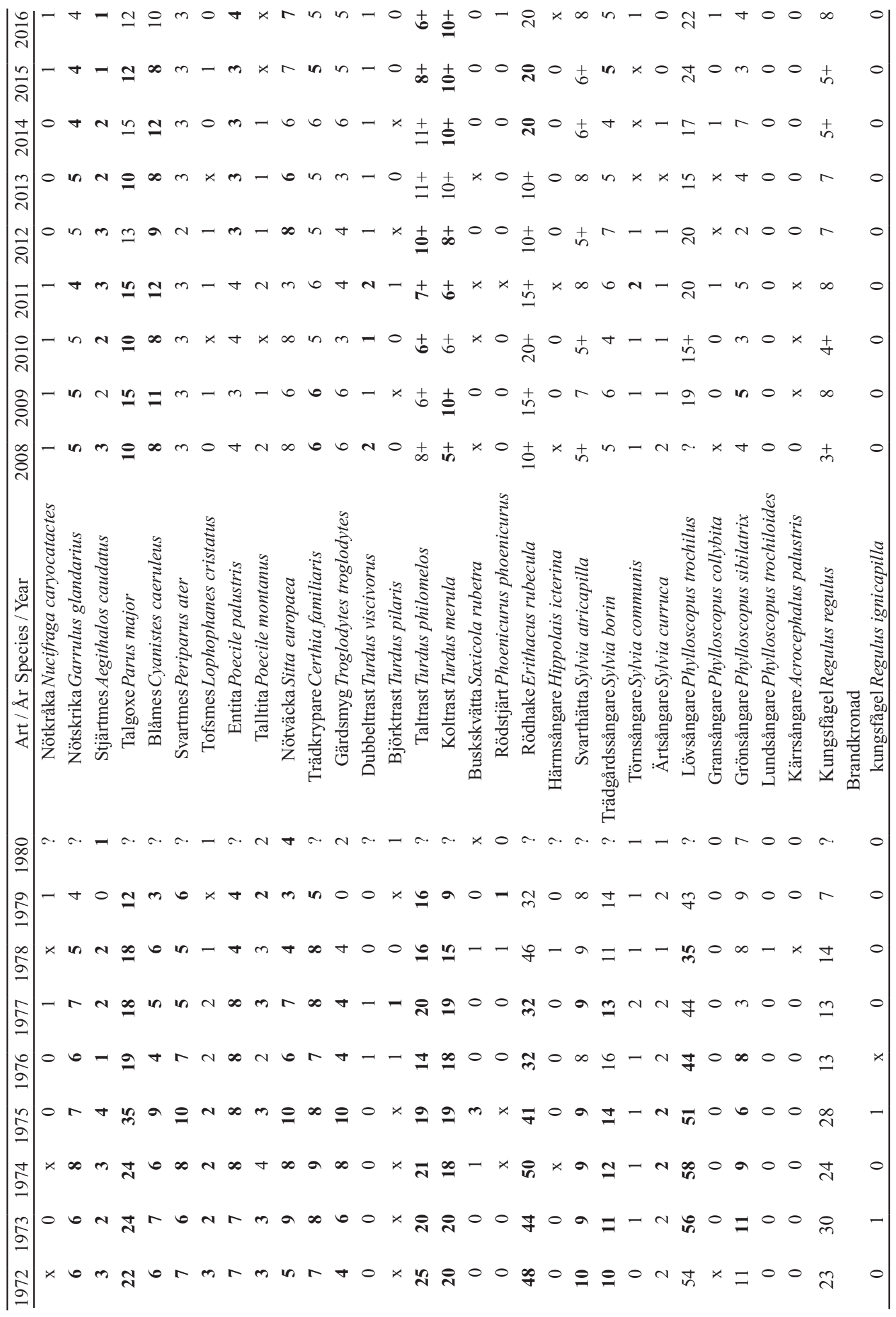




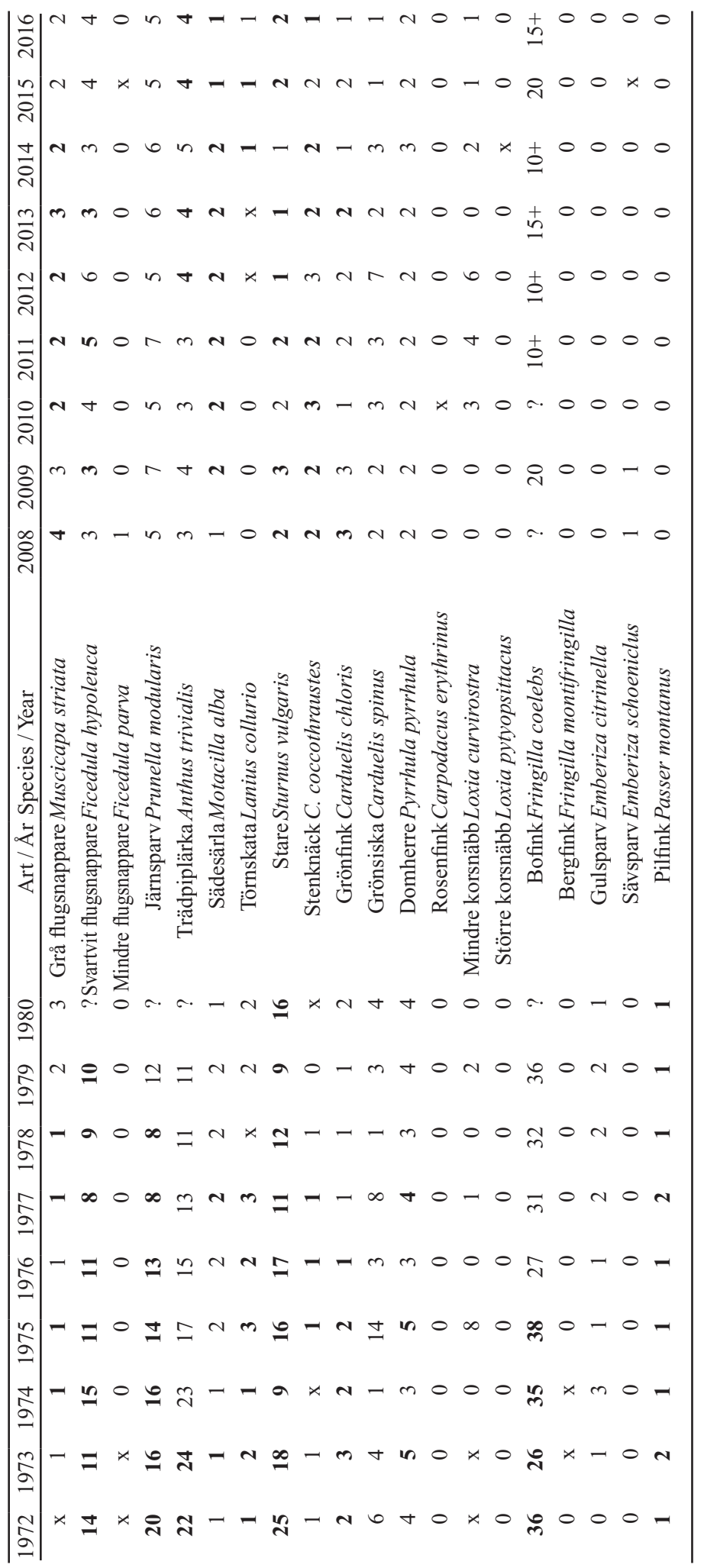

